\title{
Implementation Barriers of Inclusive Education and Their Impact on Stakeholders: A Review of the Literature
}

\author{
Stephanie Hollings \\ Jilin International Studies University, China \\ Corresponding Author: shollings88@hotmail.com \\ Citation: Hollings, S. (2021). Implementation Barriers of Inclusive Education and their Impact on Stakeholders: A \\ Review of the Literature. International Journal of Childhood Education, 2 (1), 27-45. https://doi.org/10.33422/ijce.v2i1.36
}

\begin{abstract}
The global initiatives of Education for All and inclusive education have created many unique problems as countries around the world finds ways to implement inclusive policies in order to truly be inclusive to all students. These problems have come with the realization of how the diverse stakeholders must learn to play their part in successful implementation. This study uses the literature on inclusive education from 18 articles focused on various countries and contexts to determine the main barriers towards inclusive education implementation. The three overarching barriers that emerge through the literature can be classified as societal/cultural, developmental and governmental. These barriers will be used to highlight key challenges, attitudes and perceptions in all levels of stakeholders and in a broader sense if these issues that emerge are more regional or global. Thus, showing the key issues when it comes to inclusive education implementation, policies, practices and where more concern should be placed.
\end{abstract}

Key words: education for all; global initiatives; inclusive education; inclusiveness

\section{Introduction}

Since the 1990s, there has been a global push for inclusion in education or aptly called inclusive education (IE). The foundation of which lies in many global policies and initiatives, including perhaps the most vital, the 1994 Salamanca Statement. This 1994 statement marked a fundamental shift in educational policy towards a more inclusive education or Education for All. What this called for was for all students to be accepted into mainstream schools and furthermore, each country in United Nations Educational, Scientific and Cultural Organization

(UNESCO) that signed on would be responsible for creating educational policies to enable that to happen (Booth \& Ainscow, 1998). Since then, there are have been numerous global initiatives on IE including both the UNESCO Dakar Framework for Action and the United Nations (UN) Convention on the Rights of Persons with Disability (Main, Chambers \& Sarah, 2016). However, even though decades have passed since this structural support has been laid, Al-Mahdy and Emam (2018) rightfully point out the implementation and development of inclusive education is one, if not the largest, challenges that schools and school systems throughout the world encounter. Part of that challenge for the realization and implementation of IE is that while policy practice and directions parallels can be seen throughout the world, there is still the unceasing need to make inclusive education be as Selvaraj (2015) borrowing from Mitchell (2010) stated "reflective of nationally and historically specific social, political, economic and cultural contexts" in terms of IE form, goals and depiction (p. 87). Thus, what must be taken into account is the local, global and cultural implementation barriers. 


\subsection{Literature review}

Selvaraj (2015) borrowing from Allan (2006) and Slee (2006) explains that inclusion and inclusive education are debatable ideas that have been subjected to numerous definitions and frames throughout both space and time. If these terms are looked at through the lens of the United Nations' Universal Declaration of Human Rights and International Covenants on Human Rights, it can be seen as a human right and also an international imperative (Alborz, Slee, \& Miles, 2013). According to a definition provided by UNESCO (2005), IE is "a process of addressing and responding to the diversity of needs of all learners through increasing participation in learning, cultures and communities, and reducing exclusion within and from education" (p. 13). UNESCO (2008) further defines it as "the process of strengthening the capacity of the education system to reach out to all learners" (p. 9). In this light, IE can be seen as a human right covering all learners. Yet, this is still quite ubiquitous and far-reaching, and often as will be seen, able to be manipulated by policies of eligibility.

Nevertheless, the importance of IE lies in its insistence on equity and equality in education and in society. Hence, IE has also been framed as an agenda for both equality and equity, a belief that all students are individuals and are different and that instead of simply supplying education to a specific specification of children, it should cater to the needs of each student and child (Salend, 1998; Fei, 2007). For that matter, schools, communities and countries should endeavor to establish schools in which all children are welcome and moreover a school that will make the most of each child's potential (Lei \& Deng, 2007; Yada \& Savolainen, 2017). Lo (2007) echoes this idea stating that "inclusive education advocates that mainstream schools view all teachers and students (including students with special educational needs) as equal members who can make contributions to the school" as that would allow students to be able to participate in school life, feel like they belong and be completely accepted (p. 47). IE must hence be considered as a transformation of schools and all centers of education to be inclusive of all children, including ethnic minorities, refugees, homeless children and those with disabilities, illnesses and difficulties with learning (Alborz, Slee, \& Miles, 2013). Thus, it can be said that IE is about developing inclusive communities through the attainment of high-quality education for all learners (Slee, 2010; Booth \& Ainscow, 2011). Although often the literature does not focus on such a wide variety of learners as just mentioned. This will be made abundantly clear as the literature on IE will indicate throughout this paper. It is also in many ways a drawback of such a wide term.

However, if we are to achieve these inclusive communities, there are many stakeholders that need to do their fair share. In the school itself are the school leaders and teachers. School leaders have long been linked to a school's effectiveness in implementing IE and increasing said effectiveness as they directly influence a school's culture and how innovative teaching methods and initiatives such as IE are treated throughout a school (Ainscow \& Sandhill, 2010; Al-Mahdy \& Emam, 2018). To some like Al-Mahdy and Emam (2018) school leaders are the catalyst for change for "unless the school principal is aware of the capabilities, attitudes, and interests of teachers, no new practices or initiatives will be successfully implemented" (pp.1159-1166). Teachers, although influenced by school leaders are also known to exert a substantial influence on inclusive education implementation in any given country (Kim, 2014). Forlin (2013) finds that it is imperative for teachers to have confidence in their own skills, abilities and knowledge in teaching in an inclusive environment for the inclusive approach to be implemented successfully. As Yada and Savolainen (2017) extending on Ueno and Nakamura (2011) emphasizes, a lack of knowledge, skills and training can cause teachers to stress, and even though they might see inclusive education as necessary, they might experience anxiety about actually including some students in their 
classrooms. This can, in turn, affect how the students taking part in IE get treated in the classroom by both teachers and peers, and then how that in return will have a direct effect on their families and themselves (Magumise \& Sefotho, 2020).

Parental communities and parents are also considered a central stakeholder in terms of being advocates and supporters of inclusive education, especially on behalf of their own children (Rollan \& Somerton, 2019). According to Rollan and Somerton (2019), "parental advocacy groups around the world have initiated and contributed to the recognition of the rights for educational access and other social services for children with specific educational needs" (p. 3). Wong et al. (2015) furthering the notion of de Boer, Pijl and Minnaert (2010) stress that the crucial role of parents is being a 'driving force' for the introduction, continuing support and actual inclusion of children with disabilities within mainstream education.

There is additionally the critical role of the government and often NGOs as they will be have distinct influence on the creation and enforcement of laws and policies that will either allow IE to flourish, deteriorate or never actually crystalize. As is the case in Zimbabwe, where Magumise and Sefotho (2020) discuss the impact of unclear policies on the implementation of IE policies throughout the country. Thus, each stakeholder has a vital role to play. And every stakeholder involved in the education of the child, must share the responsibility and the commitment to make sure that all the children in inclusive education succeed emotionally, academically and socially (Koay, 2014).

\section{Methods}

In this systematic review of literature, peer-reviewed articles were searched for using the databases, Sage, EBSCO, ProQuest and Taylor Francis. As it was hoped to ascertain how articles on different countries contextualize IE and who is the main focus of it, the simple keywords of inclusive education were used. Articles that mention specific student levels (primary, secondary, upper-secondary), age ranges or school types were purposefully avoided. The main criteria for selection were the exact words inclusive education, a specific country in the title of the article and a publication date of no earlier than 2010. Articles were specifically chosen on the various stakeholders in inclusive education i.e. teachers, parents, students, principals, school leaders and even NGOs. Lastly, both qualitative and quantitative studies were utilized.

This led to a total of 56 articles. Articles were then chosen for elimination that had a dual country focus. The 35 articles remaining were then coded into geographic areas which would allow for more interesting comparisons. After further contemplation, it was decided to eliminate any article investigating European and North American countries as often inclusive education is seen as a 'borrowed policy' (McDonald \& Tufue-Dolgoy, 2013) from Western countries. By doing so it was thought it would offer a different perspective on the questions being asked. From there, they were separated into groupings - Middle East, Oceania, East Asia, Eurasian/Central Asia, Southeast Asia and Africa. It is acknowledged that these groupings are not equal in terms of geographic size, cultural and historical aspects and quantity of articles. Nevertheless, they do allow for the categorization of the diverse countries as a way to be more inclusive. These articles on numerous countries would allow for a more detailed investigation on the varying factors that assess how inclusive education is portrayed in the literature, alongside the common challenges and concepts that are included in the literature on inclusive education. It must be stated that the countries chosen were limited by the articles on the countries that could be found within the search criteria. Also, as a matter of convenience, the articles will be referred to throughout the review generally with the country name or by the author's names. 
Table 1.

Articles chosen for investigation

\begin{tabular}{|c|c|c|c|c|c|}
\hline Title & $\begin{array}{c}\text { Author(s) \& } \\
\text { Year published }\end{array}$ & Country & Region & $\begin{array}{c}\text { Focus/ Participants } \\
\text { of article }\end{array}$ & $\begin{array}{c}\text { Author's research } \\
\text { method }\end{array}$ \\
\hline $\begin{array}{l}\text { Establishing the } \\
\text { foundations for an } \\
\text { inclusive education system } \\
\text { in Iraq: reflection on } \\
\text { findings from a nationwide } \\
\text { survey }\end{array}$ & $\begin{array}{l}\text { Alison Alborz, } \\
\text { Roger Slee \& } \\
\text { Susie Miles } \\
\text { (2013) }\end{array}$ & Iraq & Middle East & $\begin{array}{c}\text { Parents } \\
\text { (Commissioned by } \\
\text { UNICEF) }\end{array}$ & $\begin{array}{l}\text { Survey of } \\
\text { households, semi- } \\
\text { structured } \\
\text { interviews and } \\
\text { focus groups }\end{array}$ \\
\hline $\begin{array}{l}\text { 'Much ado about } \\
\text { something' how school } \\
\text { leaders affect attitudes } \\
\text { towards inclusive } \\
\text { education: the case of } \\
\text { Oman }\end{array}$ & $\begin{array}{l}\text { Yasser F. H. Al- } \\
\text { Mahdy \& } \\
\text { Mahmoud } \\
\text { Mohamed } \\
\text { Emam (2017) }\end{array}$ & Oman & Middle East & School leaders & $\begin{array}{l}\text { Questionnaires } \\
\text { given to } 378 \\
\text { teachers }\end{array}$ \\
\hline $\begin{array}{l}\text { Saudi children's thoughts } \\
\text { on inclusive education }\end{array}$ & $\begin{array}{l}\text { Lynn Dare, } \\
\text { Elizabeth } \\
\text { Nowicki \& } \\
\text { Huda Felimban } \\
\text { (2016) }\end{array}$ & $\begin{array}{l}\text { Saudi } \\
\text { Arabia }\end{array}$ & Middle East & $\begin{array}{l}\text { School children } \\
\text { without } \\
\text { disabilities/peers }\end{array}$ & $\begin{array}{l}\text { Interviews of } 31 \\
\text { grade 5-6 students, } \\
\text { both girls and } 34 \\
\text { boys, at an } \\
\text { inclusive education } \\
\text { school }\end{array}$ \\
\hline $\begin{array}{l}\text { Inclusive education in New } \\
\text { Zealand: policies, politics } \\
\text { and contradictions }\end{array}$ & $\begin{array}{l}\text { Judith Selvaraj } \\
\text { (2014) }\end{array}$ & $\begin{array}{c}\text { New } \\
\text { Zealand }\end{array}$ & Oceania & Policies & $\begin{array}{l}\text { Research on } \\
\text { policies and } \\
\text { literature }\end{array}$ \\
\hline $\begin{array}{l}\text { Moving Forwards, } \\
\text { Sideways or Backwards? } \\
\text { Inclusive Education in } \\
\text { Samoa }\end{array}$ & $\begin{array}{l}\text { Lex McDonald } \\
\text { \& Rasela } \\
\text { Tufue-Dolgoy } \\
\text { (2013) }\end{array}$ & Samoa & Oceania & $\begin{array}{l}\text { Parents and } \\
\text { teachers' } \\
\text { perceptions }\end{array}$ & $\begin{array}{l}\text { Interviews of } \\
\text { parents, educators } \\
\text { and community } \\
\text { leaders }\end{array}$ \\
\hline $\begin{array}{l}\text { A case study of culturally } \\
\text { informed disability- } \\
\text { inclusive education policy } \\
\text { development in the } \\
\text { Solomon Islands }\end{array}$ & $\begin{array}{l}\text { Suzanne } \\
\text { Carrington et } \\
\text { al. } \\
(2017)\end{array}$ & $\begin{array}{l}\text { Solomon } \\
\text { Islands }\end{array}$ & Oceania & $\begin{array}{l}\text { Policies and aid- } \\
\text { supported policies }\end{array}$ & $\begin{array}{l}\text { Research on } \\
\text { policies and } \\
\text { literature }\end{array}$ \\
\hline $\begin{array}{l}\text { Chinese Inclusive } \\
\text { Education: The Past, } \\
\text { Present, and Future }\end{array}$ & $\begin{array}{l}\text { Zhe Gigi An, } \\
\text { Xiaoyi Hu, and } \\
\text { Eva Horn } \\
\text { (2018) }\end{array}$ & China & East Asia & $\begin{array}{c}\text { Policies and } \\
\text { teachers }\end{array}$ & $\begin{array}{l}\text { Research on } \\
\text { literature }\end{array}$ \\
\hline $\begin{array}{l}\text { Inclusive education in } \\
\text { South Korea }\end{array}$ & $\begin{array}{l}\text { Yong-Wook } \\
\text { Kim } \\
(2014) \\
\end{array}$ & $\begin{array}{l}\text { South } \\
\text { Korea }\end{array}$ & East Asia & $\begin{array}{c}\text { Policies and } \\
\text { teachers }\end{array}$ & $\begin{array}{l}\text { Research on } \\
\text { literature }\end{array}$ \\
\hline $\begin{array}{l}\text { Japanese in-service } \\
\text { teachers' attitudes toward } \\
\text { inclusive education and } \\
\text { self-efficacy for inclusive } \\
\text { practices }\end{array}$ & $\begin{array}{l}\text { Akie Yada, } \\
\text { Hannu } \\
\text { Savolainen } \\
\text { (2017) }\end{array}$ & Japan & East Asia & In-service teachers & $\begin{array}{l}\text { Survey of } 359 \text { in- } \\
\text { service primary and } \\
\text { secondary school } \\
\text { teachers }\end{array}$ \\
\hline $\begin{array}{l}\text { Inclusive Education in } \\
\text { Georgia: Current } \\
\text { Progress and Challenges }\end{array}$ & $\begin{array}{l}\text { Nikoloz } \\
\text { Kavelashvili } \\
\text { (2017) }\end{array}$ & Georgia & $\begin{array}{c}\text { Eurasia/Central } \\
\text { Asia }\end{array}$ & $\begin{array}{l}\text { Teachers, principals } \\
\text { and other } \\
\text { stakeholders }\end{array}$ & $\begin{array}{l}\text { Semi-structured } \\
\text { interviews and } \\
\text { observations of } 5 \\
\text { teachers, } 5 \text { parents, } \\
\text { NGO and the } \\
\text { director of the } \\
\text { Department of } \\
\text { Inclusive Education }\end{array}$ \\
\hline $\begin{array}{l}\text { Inclusive education reform } \\
\text { in Kazakhstan: civil } \\
\text { society activism from the } \\
\text { bottom-up }\end{array}$ & $\begin{array}{l}\text { Kamila Rollan } \\
\& \text { Michelle } \\
\text { Somerton } \\
(2019)\end{array}$ & Kazakhstan & $\begin{array}{c}\text { Eurasia/Central } \\
\text { Asia }\end{array}$ & $\begin{array}{l}\text { Representatives of } \\
\text { NGOs involved in } \\
\text { inclusive education }\end{array}$ & $\begin{array}{l}\text { Interviews of } 7 \\
\text { Kazak NGO } \\
\text { representatives }\end{array}$ \\
\hline $\begin{array}{l}\text { Inclusion in Brunei } \\
\text { Darussalam: the role of } \\
\text { teacher education }\end{array}$ & $\begin{array}{l}\text { Teng Leong } \\
\text { Koay } \\
(2014)\end{array}$ & Brunei & Southeast Asia & Teacher (education) & $\begin{array}{l}\text { Research on } \\
\text { literature }\end{array}$ \\
\hline
\end{tabular}




\begin{tabular}{|c|c|c|c|c|c|}
\hline Title & $\begin{array}{c}\text { Author(s) \& } \\
\text { Year published }\end{array}$ & Country & Region & $\begin{array}{c}\text { Focus/ Participants } \\
\text { of article }\end{array}$ & $\begin{array}{c}\text { Author's research } \\
\text { method }\end{array}$ \\
\hline $\begin{array}{l}\text { Inclusive education in } \\
\text { Malaysia: policy and } \\
\text { practice }\end{array}$ & $\begin{array}{l}\text { Zalizan M. } \\
\text { Jelas \& } \\
\text { Manisah Mohd } \\
\text { Ali } \\
\text { (2014) }\end{array}$ & Malaysia & Southeast Asia & Policy and practice & $\begin{array}{l}\text { Research on policy } \\
\text { and literature }\end{array}$ \\
\hline $\begin{array}{l}\text { Parental perspectives and } \\
\text { challenges in inclusive } \\
\text { education in Singapore }\end{array}$ & $\begin{array}{l}\text { Meng Ee Wong } \\
\text { et al. } \\
(2015)\end{array}$ & Singapore & Southeast Asia & Parents & $\begin{array}{l}\text { Interviews of } 13 \\
\text { parents with } \\
\text { children with mild } \\
\text { disabilities }\end{array}$ \\
\hline $\begin{array}{l}\text { Parent and teacher } \\
\text { perceptions of inclusive } \\
\text { education in Zimbabwe }\end{array}$ & $\begin{array}{l}\text { Johnson } \\
\text { Magumise \& } \\
\text { Maximus M. } \\
\text { Sefotho } \\
(2020)\end{array}$ & Zimbabwe & Africa & $\begin{array}{l}\text { Teachers and } \\
\text { parents }\end{array}$ & $\begin{array}{l}\text { Focus group } \\
\text { discussions and } \\
\text { interviews of } 12 \\
\text { teachers and } 12 \\
\text { parents }\end{array}$ \\
\hline $\begin{array}{l}\text { Inclusive education in } \\
\text { Nigeria: exploring } \\
\text { parental attitude, } \\
\text { knowledge and perceived } \\
\text { social norms influencing } \\
\text { implementation }\end{array}$ & $\begin{array}{l}\text { Eric Lawer } \\
\text { Torgbenu et al. } \\
\text { (2019) }\end{array}$ & Nigeria & Africa & Parents & $\begin{array}{l}\text { Questionnaires } \\
\text { given to } 708 \\
\text { parents (both with } \\
\text { and without } \\
\text { children with } \\
\text { disabilities) }\end{array}$ \\
\hline $\begin{array}{l}\text { Supporting the transition } \\
\text { to inclusive education: } \\
\text { teachers' attitudes to } \\
\text { inclusion in the Seychelles }\end{array}$ & $\begin{array}{l}\text { Susan Main, } \\
\text { Dianne J. } \\
\text { Chambers \& } \\
\text { Paulette Sarah } \\
\text { (2016) } \\
\end{array}$ & Seychelles & Africa & Teachers & $\begin{array}{l}\text { Questionnaires } \\
\text { given to in-service } \\
\text { teachers doing an } \\
\text { inclusive education } \\
\text { course }\end{array}$ \\
\hline $\begin{array}{l}\text { Teachers' self-efficacy } \\
\text { beliefs, attitudes and } \\
\text { concerns about } \\
\text { implementing inclusive } \\
\text { education in Ghana }\end{array}$ & $\begin{array}{l}\text { Ahmed Bawa } \\
\text { Kuyini, } \\
\text { Ishaverlal } \\
\text { (Ishwar) Desai, } \\
\text { and Umesh } \\
\text { Sharma (2018) }\end{array}$ & Ghana & Africa & Teachers & $\begin{array}{l}\text { Questionnaires } \\
\text { given to } 134 \\
\text { primary school } \\
\text { teachers }\end{array}$ \\
\hline
\end{tabular}

\subsection{Purpose of study}

This study hopes that through reviewing 18 articles on inclusive education focusing on 18 distinct but often geographically or historically similar countries, more perspective can be shown on how diverse authors writing about different countries chose to portray inclusive education. While these differences could have taken any multitude of shapes, this review will focus on them in terms of barriers faced by the individual country and how that affects the various levels of stakeholders. By looking at the individual articles, written about different countries and stakeholders, much can be seen about the key themes emerging from common challenges, concerns and limitations of inclusive education as a whole (including stakeholders, policies and implementations). By separating them into geographic regions for the purpose of coding, themes did emerge in that specific region, which allowed for more direct comparison not only within that specific region but in the literature as a whole. While acknowledging that each country is different, with disparate cultures, histories and challenges, these geographic regions will still be used as a superficial way to make sure that an assorted range of countries is used and as a way to categorize them in a more manageable grouping. However, as the results will show, these regions oft share many similarities. Although this does not necessarily correlate to geographical trends as for that to be looked at, the scope of the review must be increased. Nevertheless, By looking at 18 different countries, each with unique national policies, histories, cultures, economic standings, varied levels of development, etc., not only did singular realities emerge but overarching barriers materialize. This 
is, of course, the focus on the review and a worthy starting point in which to delve into the literature on inclusive education.

Therefore, this is a two-pronged investigation into first the barriers that emerge throughout these 18 articles and in return the challenges, perceptions and limitations on the stakeholders as a result of those barriers.

\subsection{Research questions}

1. What overarching barriers can be seen to emerge throughout these articles?

2. How do these barriers that emerge in the geographic region or in the wider scope shed light on key concerns, attitudes and challenges in inclusive education?

3. Furthermore, what do these barriers say about the field as a whole in terms of stakeholders and their responsibilities?

\section{Results}

The articles all showed a variety of barriers that could be separated into three overarching categories: societal/cultural, developmental and governmental. Cultural and societal barriers include challenges and perceptions caused by cultural/social stigmas, religion, school culture and lack of public awareness; developmental barriers include economic challenges, such as educational infrastructure, lack of resources and also teacher training; and governmental barriers will focus on policies such as the implementation and the borrowing of them. These barriers are shown in many different angles and light depending on the country's context and how the author chooses to portray them. Some appear to be more regional, some more global and some more reminiscent of the developmental level of the country. Yet, all shed light on many of the most pressing issues that seem to plague successful IE implementation, and more importantly global issues of challenges of attitudes and perceptions of IE and the stakeholders of IE.

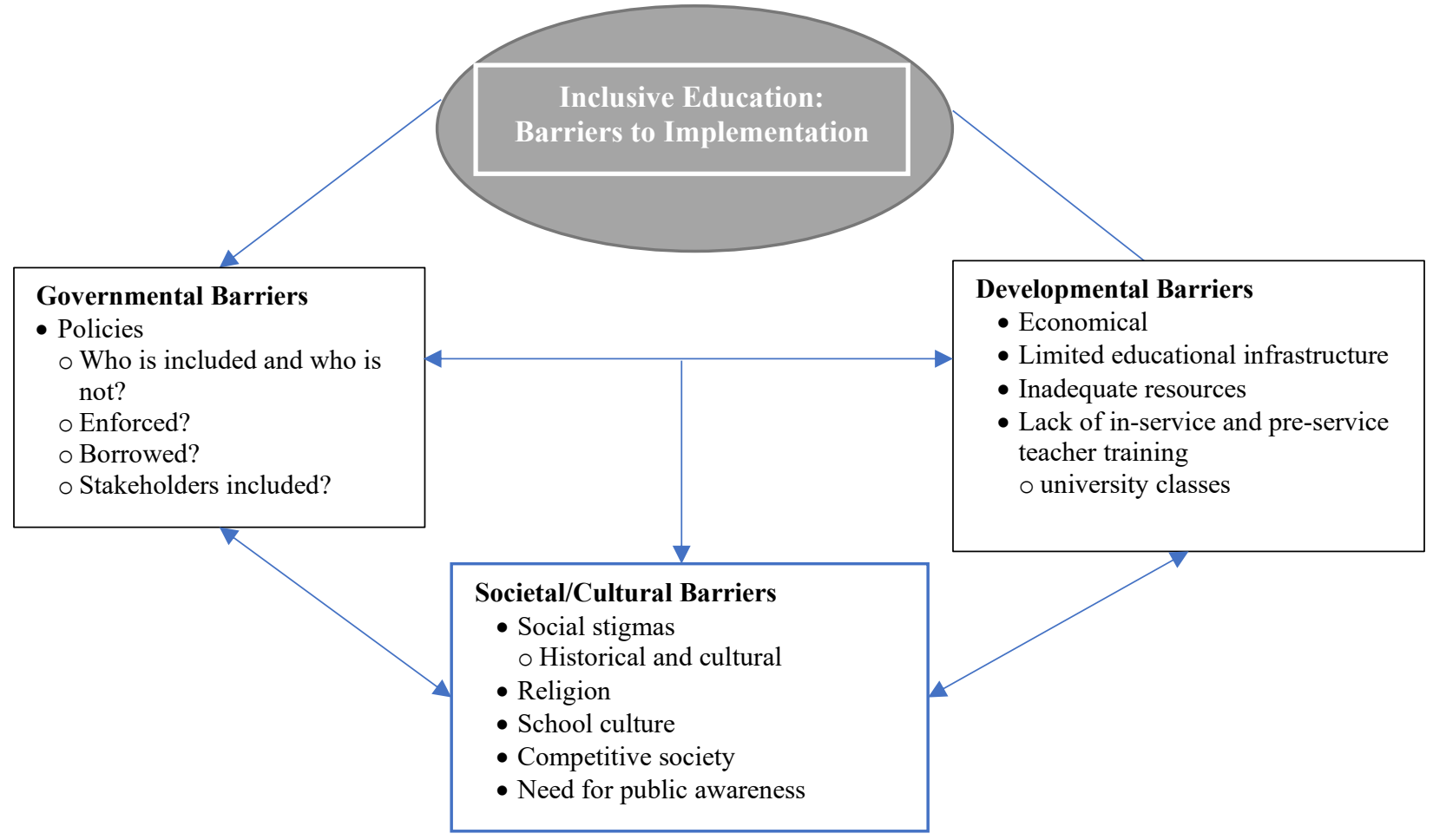

Figure 1. Inclusive Education: Barriers to Implementation 


\subsection{Societal/cultural barriers}

The most prevalent barriers mentioned throughout these 18 articles can be seen as issues of societal/cultural barriers which can be seen to affect nearly every single stakeholder in IE implementation.

\subsubsection{Cultural stigmas/social stigmas}

All three articles on Middle Eastern countries coincidently looked at inclusive education through the lens of disabilities. In the article on Iraq that is both in terms of physical and mental handicaps, the physical stemming from war and the effects of the war. This once again hints at the numerous realities countries face in terms of who is included in IE and where those realities stem from. There was additionally a focus on the cultural differences in defining disability and how in Arabic disability is often seen as meaning defective (Alborz et al., 2013). All three articles to some extent mentioned social stigmas or traditional values as barriers to inclusive education. In the case of Iraq, it was isolation, marginalization and stigmas associated with children with disabilities; in Oman, it was social stigmas and traditional values of tribal allegiance; while in Saudi Arabia the children interviewed talked about how many of them perceived children with disabilities as 'academically inferior', “weak, slow, and not clever" (Dare, Nowicki, \& Felimban, 2017, p. 537). Likewise, Alborz, Slee and Miles (2013) and Al-Mahdy and Emam (2018) noted similar occurrences in thoughts amongst the people of their studies. Along these same lines is Kim's (2014) discussion on the lingering tendency of South Koreans to view disabilities "as an individualized pathology or disease" and with a generally negative attitude towards disabled children (p. 987). Hence, this problem can be regarded as perhaps a wider global issue.

Historical legacies additionally can be considered catalysts for social stigmas such as seen in the case of both Eurasian/Central Asian articles. As both, the countries in these articles were postSoviet Union countries it would be remiss to ignore the legacy of how special education was handled in the Soviet Union. This approach was described by Kavelashvili $(2017$, p. 92) as a 'diagnostic therapeutic approach' or 'medical model' (p. 92) and by Rollan \& Somerton (2018) as a "special or 'correctional' approach" (p. 1). To further expand on this process Kavelashvili (2017) states that this process designated disabled children as people who should not be incorporated into 'mainstream society'. Instead, it was believed that they should have separate opportunities made available to them in an alternative world (Kavelashvili, 2017). This would often include the special needs child being "separated from their peers in a 'so-called' correctional institution of at home by special educator referred to as 'defectologists"” (Rollan \& Somerton, 2018, p. 1).

In Georgia, it is conceivably no surprise that this legacy has resulted in an overall dearth of preparedness by people in the country to accept the people/children who are different than them. This as Kavelashvili (2017) explains has led many parents of special educational needs (SEN) children to be fearful that not only will their children be embarrassed by other children in the classroom but also inept at acquiring the life skills gained from an academic classroom. However, as Wong et al. (2015) shows these fears on behalf of parents are not geographically isolated fears. Wong et al. (2015) found similar results on parental worries in Singapore. Yet, the parents in Singapore present a different caveat in regards to presenting a more broad comprehension of the importance of IE. As Wong et al. (2105) notes that although some parents presented their anxiety about their child with disabilities being part of mainstream education, many recognized that in order to become 'full and equal' members of Singapore society, this experience in mainstream education during childhood would be especially indispensable for children with special needs ( $p$. 93). The main concern by parents seemed to reflect a deeper concern than just policies, school 
support or teacher preparation but "whether their children with disabilities will emerge from school as contributing individuals in society" (Wong et al., 2015, p. 94). Thus, these parental fears could be said to result from numerous cultural realities in the various countries and while not the same in each circumstance, as the stigmas and societies are different, it remains a barrier, nonetheless. And as other studies, including the one done on Saudi Arabia, a rather pertinent barrier.

In Zimbabwe where "inclusion is yet to flourish", parents and teachers expressed three perceptions - positive, neutral and negative (Magumise \& Sefotho, 2020, pp. 1-3). Those with positive perceptions expressed many of the same ideas as Singaporean parents in Wong et al. (2015). This was seen in the notions that IE "allows for equal opportunities among learners", especially learners "prone to marginalization, exclusion and underachievement" and as being more beneficial for students than being placed in secluded special education classes (Magumise \& Sefotho, 2020, pp. 5-8). Those with mixed perceptions focused on 'good and bad days', of days where everything went well and days with discrimination and labeling by some peers and teachers (Magumise \& Sefotho, 2020, p. 8). Those with negative perceptions noted how their child "could hardly catch up with their "normal' peers", the pressure to pass nationally recognized examinations and the vulnerability of the special need's child to mistreatment like neglect, bullies and being tormented, which brought about great anxiety for the children and their parents (Magumise \& Sefotho, 2020, p. 9). Thoughts that were reflected by the stories elucidated from Saudi children (Dare, Nowicki, \& Felimban, 2017) in which concerns were warranted and the concerns of the parents in Singapore (Wong et al., 2015). These also highlight the multi-dimensional validity and causes of such parental anxieties.

Echoing many of these parental perceptions is the survey of Nigerian parents, who overall had a 'slightly positive perception' but limited knowledge of IE and had to fight the Nigerian tendency towards stigmatizations of children with disabilities as liabilities unable to learn (Torgbenu et al, 2019, pp. 1-11). Thus, showing that this barrier exists throughout many of the geographic areas focused on in numerous forms. While some are quite similar, each maintains a unique foundation that would need to be addressed.

\subsubsection{Religion}

In many ways, religion and beliefs can be considered a barrier to successful IE implementation. Nevertheless, it can also be as will be shown, an element and layer of a society deeply connected with successful IE implementation and acceptance. Both the articles on Iraq and Oman mentioned Islamic values of kindness and mercifulness and how they were in line with inclusive education initiatives (Alborz, Slee, \& Miles, 2013; Al-Mahdy \& Emam, 2018). The article on Samoa reflected similar beliefs about the principle of Fa'aSamoa. Fa'aSamoa being "the heritage of the people", a "mindset embedded in the political, social, and economic systems of Samoa" which entails "specific guidelines with regard to family, community, and Christian church" (McDonald \& Tufue-Dolgoy, 2013, pp. 270-271). The three guiding principles of Fa'aSamoa are fa'aaloalo (humility/reverence), ava (respect) and alofa (love), which are seen as compatible with the principles of inclusive education (McDonald \& Tufue-Dolgoy, 2013). However, as McDonald and Tufue-Dolgoy (2013) following upon the work of Ngan-Woo (1985) supports that this is particularly demanding upon a system that has limited resources and educators with limited skills. For example, a country like Samoa. These ties of community and family were also explored by Kim (2014) in regards to South Korea. As Kim (2014) explains, South Korea is both culturally and history infused with religions and philosophies of Taoism, Buddhism and Confucianism. Thus, it is these deeply embedded family and community bonds, that Kim (2014) observes as "traits 
which extend naturally and informally to safeguarding its more vulnerable members" (p. 988). Hence, people with special needs. While these guiding principles all are in line with the guiding principles of IE, they can also be seen to add another needed layer of IE policy. Such as what was focused on by McDonald and Tufue-Dolgoy (2013), were much like Islamic principles (Iraq and Oman articles) and Confucian principles (China and South Korea articles), Fa'aSamoa is in theory, in line with principles of IE but generates the need of special country-specific characteristics when implementing inclusive education policies. So, as much as this is a societal and cultural barrier, it is also an intrinsic governmental barrier and at the same time a possible benefit. Thus, it will later be discussed as such.

\subsubsection{School culture and competitive society}

School culture emerged in these articles as a key barrier in a few countries, generally in one continent. In the article on China, it was noted that some of the basic features of Chinese public schools are large class size and inflexible class structures (An, Hu, \& Horn, 2018). Likewise, as mentioned by Yada and Savolainen (2017) in their survey of Japanese teachers, a notable challenge in Japan is large class sizes. Yada and Savolainen (2016) go on to explain that large classes can affect teacher's self-efficacy and make it more difficult to implement IE in a classroom as the teachers might be unable to provide adequate support for all the children. This barrier was furthermore acknowledged by Kim (2014) who mentioned large class sizes and to a larger extent a 'competition-oriented school culture' (pp. 984). Extending on this competition-focused school culture, many of these articles show that it is not solely a South Korean issue and hence a large possible IE barrier.

Torgbenu et al. (2019) also makes mention of the examination-based aspect of the Nigerian school system and the effects of IE on both parents with and without children with disabilities. As the paramount concern for parents whose children do not have disabilities is if IE will cause negative effects on their children's learning experiences (Torgbenu et al., 2019). Jeles \& Ali (2014) point out that school's 'competition priorities' have veered Malaysian IE policies towards default 'exclusionary processes and practices', in what they dub a 'culture of elitism' (pp. 997-999). Wong et al. (2015) acknowledge that Singapore is a small country with limited resources, except people, which leads to 'two major ideologies' guiding Singaporean education - multiculturalism and meritocracy (p. 87). This leads to a 'competitive education system' where stress is prominently featured and although Singapore is on the precept of both the East and West, "it is still at heart an East Asian society in which Confucian values such as academic excellence predominates" (Wong et al., 2015, p. 87). In Malaysia, Jelas and Ali (2014) point out how education is largely driven by an 'examination-oriented system' embodied by curriculum inflexibility and the stress to gain high examination scores. As Jelas and Ali (2014) explicate this is problematic to reconcile with IE, especially when "media reports on schools and students' performance intensify competition and further marginalize SEN students, who to a large extent, are not expected to compete" (pp. 9991000). Leading, Jelas \& Ali (2014) to encourage policies in IE in Malaysia that "work with the social, cultural and educational traditions, and philosophy that are indigenous to local school cultures and the larger society" that "reflect the unique needs and characteristics of Malaysians" (p. 1001). Thus, proving the interconnectedness of many of these barriers, which stem not only from school culture but historical factors, ideologies and values to social stigmas of children with special needs. Which often in competitive societies, with limited educational resources, these children with special needs are oft not expected to be able to compete (Jelas \& Ali, 2014) or seen as taking time away from the other students in the class. Part of this is explained by Stevens and 
Wurf (2020) as IE implemented successfully would require a greater need for a teacher to focus more on those students with special needs. As many of these articles have stated, there are considerable difficulties in that being feasible without significant barriers being overcome.

\subsubsection{Lack of public awareness}

A problem emphasized in many of these articles is a consistent lack of public awareness of IE and of children with disabilities in general. Two of these articles were the articles on Georgia and Kazakhstan. Kavelashvili (2017) expresses that part of this issue comes from the rather new status as an independent country and thus have an absence of practical experiences in IE implementation. One element that was unique to these two articles was the conduction of interviews with NGO members in both respective countries, although it must be noted that these interviews were only part of the stakeholders interviewed in the article on Georgia. Focusing on Georgia, the key issues that arose in the article, frequently on behalf of the NGO workers, were teachers' lack of skills, poor infrastructure, transportation problems, a lack of set SEN standards, adverse perceptions of 'mainstream parents' in regards to IE and an overall dearth of preparedness by people in the country to accept the people/children who are different than them (Kavelashvili, 2017). Often these issues culminate in negative attitudes towards children with disabilities as a result of a lack of public awareness (Kavelashvili, 2017). Culminating in a general 'pessimistic attitude' about the 'social discrimination and classical intolerance' of these children in both the society and in mainstream schools (Kavelashvili, 2017, pp. 98). The NGO workers in Kazakhstan that were interviewed noted some similar trends about the need for policy formation, revision and reenactment and in similitude with Georgia, improvements in practice and culture. For the cultural aspects, the study participants all mentioned both the societal obstacles these children confront, as well as the NGO's influence in continuing to raise awareness on their behalf (Rollan \& Somerton, 2018). Many NGO employees surveyed additionally made mention of awareness campaigns on the rights of these children in gaining an inclusive education and to try to fight against 'traditional views of segregation' (Rollan \& Somerton, 2018, p. 13). As it was deemed through the encouragement of social inclusion initiatives such as sports and art programs, that are inclusive of both special need's children and non-special needs children, that this will allow all the children to make new friends and potentially develop new social skills (Rollan \& Somerton, 2018). Hence, public awareness would be increased. Both these articles focused on the issues of newly-formed post-Soviet Union countries and the need for more public awareness, challenging historical views of segregation and better involvement from teachers, parents, schools and NGOs in implementing inclusive education.

Magmuise and Sefotho (2020) and Torgbenu et al. (2019) also mention the need for awareness, both public awareness and parental awareness. In their survey of parents and teachers, Magumise and Sefotho (2020) note that while the perceptions vary, they are definitely affected by the general public's limited awareness, insufficient resources and teacher training that is improper for dealing with IE. These three drawbacks were expanded on during their numerous interviews. Perhaps the most telling was one participant who reflected that "inclusive education is a good idea but in Zimbabwe and the whole of Zimbabwe it is currently marred with challenges that include inadequate resources, yet to be upgraded teacher training curriculum and lack of awareness among the general people who are an important stakeholder in inclusive education" (Magmusie \& Sefotho 2020 , p. 10). Reflecting many of these parental perceptions is the survey conducted by Torgbenu et al. (2019) of Nigerian parents, who overall had a 'slightly positive perception' but limited knowledge of IE (p. 1). What Torgbenu et al. (2019) found was that "knowledge emerged as a 
significant predictor of attitudes", with the higher the knowledge the higher the perception of IE (p. 10). Hence, the more public awareness there is, the more the barrier decreases. However to state this as being just a societal issue limits the interconnection it has to developmental and governmental barriers.

The need for public awareness was a theme echoed throughout the articles on Kazakhstan, Malaysia, Georgia, Zimbabwe and Nigeria. In the Georgian context the article explains that more attention should be paid to the 'unpreparedness' in society to accept people who are different as this lack of public awareness spreads to the accepting of including SEN children into mainstream schools (Kavelashvili, 2017). Jelas and Ali (2014) state that in Malaysia, at both the local and national level, there is a need to strengthen the public awareness and public acceptance of creating 'equal opportunities' for every child. They suggest that this can come from the websites of the social and educational institutions as well as the media (Jelas \& Ali, 2014). The parents and teachers studied by Magumise and Sefotho (2020) highlights that beyond just the lack of public awareness, there is a lack of awareness among vital IE stakeholders. It is evident in a percentage of these articles, regardless of their geographic region, that awareness of IE and people with SEN needs to be exponentially increased within the public and the community at large. Yet, as many of these articles, the key stakeholders also are part of those that could need more awareness. As successful IE will require all to come together, understanding the importance of it, for it to work and to overcome any historical or cultural legacies. And as these articles show, until that happens, it will just be a nice idea.

\subsection{Developmental barriers}

Developmental barriers have also been shown in these articles to be a hindrance to the implementation of IE. These barriers will be looked at through the scope of the economical level of the country, which would influence infrastructure and often create a lack of resources and teacher preparation for IE (in-service and pre-service, including mandatory university classes on IE and special education).

\subsubsection{Educational infrastructure and lack of resources}

These two issues were reiterated throughout many articles. One aspect that was previously cited was Fa'aSamoa, which was referred to as a cultural and religious aspect of Samoa compatible with the principles of inclusive education but at the same time seen as particularly demanding upon a system that has limited resources and educators with limited skills (Ngan-Woo, 1985; McDonald \& Tufue-Dolgoy, 2013). This alludes to a prominent barrier. The barrier that even if cultural aspects are in line with IE, limited resources can make it hard to implement. Alborz et al. (2013) likewise touched upon this. By focusing on how Islamic principles are in line with IE principles, there is also the necessity to realize the realities of infrastructure as a significant concern for countries like Iraq (Alborz et al., 2013). However, Alborz et al. (2013) do point out that as Clinton (2009) states there is the opportunity to "build back better" while rebuilding Iraqi education infrastructure to be able to better support IE, especially disabled children (p. 955).

Kavelashvili (2017) and Rollan and Somerton (2018) mentioned similar sentiments about poor infrastructure, transportation problems and a lack of SEN standards in IE in Georgia and Kazakhstan (pp. 95-98). In the Zimbabwean context, Maguise and Sefotho (2018) expand on these issues and further highlight the obstacles faced when it comes to a shortage of resources by quoting one of the participants stating that 
Every time I hear the phrase 'inclusive education' I think of our preparedness as schools, communities and the entire nation to adopt the idea of inclusivity in the education system. Despite the palatability and popularity of the idea, I still personally am of the opinion that schools, communities and the whole nation are too ill-resourced to do fruitful inclusive education. Looking at factors such as teacher training, teacher to pupil ratio and resource shortage in general, I wonder if time is really ripe for us to embrace and implement inclusive education (p.10).

\subsubsection{Teacher training}

The need for teacher development was a theme in almost every article (except for the articles on Saudi Arabia, Kazakhstan, Nigeria, Singapore and Malaysia). Main, Chambers and Sarah (2016) explain this by acknowledging that 'teacher's beliefs, attitudes and concerns about including children with disability in regular classrooms have an impact on their perceived self-efficacy for inclusive practice and, subsequently, their willingness to include children with disability in their classrooms" (p. 1274). As follows, with IE, the role of the teacher cannot be overstated. However, the focus on teachers occurs in many different avenues. Interestingly, even those articles that are not exclusively dedicated to teachers still maintain brief statements on the deficiency of teacher preparation (both pre-service and in-service) and the general IE prerequisite of better teacher preparation (Alborz, Slee, Miles 2013; An, Hu, \& Horn, 2018). For example, Alborz, Slee and Miles (2013) provided context into how many stakeholders in their study believed that the teachers currently employed in the schools oft possessed inadequate and dated knowledge of both IE and disabilities. Thus, there remained the necessity for developing new approaches to curriculum design and teaching that would be more inclusive of the educational demands for all children, and this would only be possible by investing in infrastructure and fostering teacher training (Alborz, Slee, \& Miles, 2013). This cannot though be considered a barrier for one specific country, especially teacher education and preparing teachers to find self-efficacy within an inclusive classroom.

The articles on the Seychelles and Ghana both focused on teachers and the importance of teachers' beliefs, attitudes and self-efficacy in implementing successful IE (Main, Chambers, \& Sarah, 2016; Kuyinia, Desai, \& Sharma, 2018). The Seychelles until 2015 had not yet implemented IE but was in the process of it, and Main, Chambers and Sarah (2016) discovered by investigating teachers taking a course in inclusive education that exposure to children with disabilities both increased and decreased self-efficacy. While perhaps contradictory, this can shed light on the reality for many teachers worldwide. Main, Chamber and Sarah (2016) went on to clarify that self-efficacy was increased with a heightened sense of self-efficacy to teach inclusively and collaborative with parents and other stakeholders in a child's education but self-efficacy was decreased in teachers "making their expectations clear", "calming disruptive \& noisy students" and getting students to follow class rules (pp. 1277-1279). The questionnaire by Kuyinia, Desai and Sharma (2018) detected some similar trends with teacher self-efficacy being low in "managing student's disruptive behavior", using "positive behavior strategies to prevent inappropriate behavior" and using "specific instructional strategies for peer or small group learning", among a few other areas (p. 12). Yet, the Ghanaian teachers still showed high self-efficacy beliefs about IE and that by partaking in special education training, regardless of any actual experience being a teacher for special needs children, was of a significant relationship to individual beliefs in self-efficacy (Kuyinia, Desai, \& Sharma, 2018). The Japanese teachers surveyed echoed similar sentiments about not receiving adequate teacher training (Yada \& Savolainen, 2017, p. 223). They surveyed 
the teachers to be able to go more in-depth and learn about the high level of anxiety of Japanese teachers faced about including children with disabilities and overall "low self-efficacy for inclusive practices" and their practice in general (Yada \& Savolainen, 2017, p. 226). There seems to be some distinct correlation between the necessity for increasing teacher's self-efficacy and experiences with special needs students to prevent teacher anxiety, especially the type of anxiety that might come from the behaviors mentioned above. Thus, highlighting the reason teacher training is paramount for IE and why it is a tantamount developmental barrier alongside increased infrastructure. However, like Koay (2014) notes that there must be more collaboration between special education and regular teachers, more specialist training for not just special needs teachers but all the stakeholders - the administrators, Ministries of Education and even the community. As awareness must be increased in all level, the school, the community and even the government.

\subsection{Governmental Barriers}

As mentioned in the article on Brunei Darussalam, government and governmental policies can play an important role or barrier in teacher education but there is more to their roles than just that. Governments are responsible for creating policies that will implement and enforce IE policies, which can be a problem if the policies are lacking, create eligibility problems or are borrowed.

\subsubsection{Policies}

One of the main issues, when it comes to policies, is either a general deficit of policies or the paucity of enforcing policies. In the China article, the authors mention that one of the main hurdles to the implementation of IE is the fact that public schools are not obligated nor mandated to accept students with disabilities (An, Hu, \& Horn, 2018). An, Hu and Horn (2018) cite the National People's Congress of 2016 which states that regular or mainstream schools only need to "accept students with disabilities who are capable of receiving general education" (p. 119). Using broad and vague statements leads to what Slee (1996) refers to as a 'conditionality of inclusive education'. The articles by Jelas and Ali (2014) and Wong et al. (2015), although one focused on policy and one on parents, raised many comparable points. They focused on how not all children with special needs will be included as often there are specific eligibility requirements based on the assumption "that there are children who are uneducable within the public-school systems" (Jelas \& Ali, 2014, p. 994). Those deemed 'uneducable' are oft those with severe disabilities (Jelas \& Ali, 2014; Wong et al., 2015). Once again highlighting the idea of eligibility dilemmas (Jelas \& Ali, 2014) and what can happen with defunct, broad and unenforced policies. That is perhaps why these policies need to not be simply borrowed.

\subsubsection{Policy borrowing}

Many of the articles looked at inclusive education as a 'Western-driven ideology' (Carrington et al., 2017). In particular, not only did all three articles featured on countries from Oceania focus on policy but they also emphasized the notion of 'borrowing' inclusive education policies instead of developing more culturally informed policies (McDonald \& Tufue-Dolgoy, 2013; Carrington et al., 2017). The article on the Solomon Islands was more looking at the idea of developing a bottomup approach to IE that could consider values of the "local people, culture, and context" (Carrington et al., 2017, p. 496). In the article on New Zealand, similar beliefs were expressed by the author on terms of how to create IE policies that are reflexive of "nationally and historically specific social, political, economic and cultural contexts", in particular, attention should be paid to indigenous perspectives on specific issues encountered by indigenous New Zealanders such as the 
Māori and Pasifika and their learners with SEN and disabilities (Selvaraj, 2015, pp. 87-94). In the same vein, the article on Samoa, likewise concluded that the Samoan government should create IE policies that would rely on Samoan characteristics and Fa'aSamoa (Samoan way) instead of indiscriminately borrowing policies (McDonald \& Tufue-Dolgoy, 2013). Fa'aSamoa as has been mentioned above, is a peak example of the converging of barriers that IE is presented with when policy borrowing instead of fashioning country-specific policies.

What these articles seem to implore is the cruciality of crafting IE policies that reflect the culture, history and special characteristics of a specific country context and not just borrowing them. Yet, it was not just unique to these three articles. Kim (2004), much like the articles about Oceania countries, mentions the need for South Korea that like most countries has a unique education foundation and background to have IE policies approached in a Korean way. Kim (2004) explains that the success in South Korea of IE is dependent on political, cultural, economic and social realities. Jelas \& Ali (2014) also saw the need to encourage policies in IE in Malaysia that "work with the social, cultural and educational traditions, and philosophy that are indigenous to local school cultures and the larger society" that "reflect the unique needs and characteristics of Malaysians" (p. 1001). Policies must reflect these conditions. Thus, these conditions can be a barrier, yet they can also be a catalyst for designing innovative and country-specific policies.

Many authors expressed the concern of IE being a Western ideology. Furthermore, that the countries they were investigating were simply borrowing policies instead of taking into consideration their own unique needs, history and culture (McDonald \& Tufue-Dolgoy, 2014; Selvaraj, 2014; Kim, 2014; Carrington et al., 2017). As Carrington et al. (2017) acknowledges that when it comes to implementation there is a necessity for "culturally informed policy development" (p. 496). This theme was especially prevalent in the articles on Oceania but also was considered in the articles on South Korea and Malaysia.

\subsection{Overarching barriers}

What can be seen is that even within these three levels of barriers, there is much interconnectedness. Governmental barriers are not isolated from societal or cultural barriers nor are they isolated from developmental barriers. For example public awareness campaigns, while they could be started by NGOs, there is still the need for government sponsored public education as a tool for generating awareness, as was noted by Torgbenu et al. (2019). Continuing on with the example of increasing awareness, it must be addressed that this compulsion for public awareness is not solely because of historical and societal barriers. There are also developmental and governmental barriers intrinsically connected. This multi-facetedness should not be ignored as it will have imperative bearings on every level of stakeholder in IE implementation.

\section{Discussion}

What the results show is that there are three levels of barriers for stakeholders in IE. As mentioned above, these levels are also not distinct from one another but often overlap and are interconnected. Cultural and societal barriers will affect governmental policies, which in return will be affected by developmental barriers. In fact, governmental policies should take into consideration the societal and cultural barriers and aspects that can be seen in line with IE alongside aspects of developmental barriers. None of these issues are isolated, for example, the way that society views children with disabilities historically have the tendency to linger. Religion and cultural beliefs also have an effect, such as was the case with Islam, Confucianism, Taoism and Fa'aSamoa. While these can be seen as beneficial for IE, they are also limited by policies, lack of resources, inadequate 
infrastructure and cultural and historical realities. As Selvaraj (2014) mentions, there is often a "disjuncture between rhetoric and reality" in IE because of "fiscal and ideological constraints of any policy framework" (p. 87). Carrington et al. (2017) relatedly notes the need for any IE policy to be implemented under "an understanding of both the socio-cultural contexts and the lived realities of the people" (p. 503). Without such an understanding, IE can be seen as nothing more than a 'distant dream', a 'well-intentioned policy' (Selvaraj, 2014, pp. 96-97) or merely a borrowed policy (McDonald \& Tufue-Dolgoy, 2013).

Furthermore, these articles focused on a comprehensive range of stakeholders and different themes about concerns, attitudes and challenges seemed to arise. Most of them can be categorized into three barriers: societal/cultural, developmental and governmental. This range of issues addressed topics such as policy borrowing, parental concerns/fears/anxieties on ill-treatment of their child and if their child would be fully included in society (Wong et al., 2015; Main, Chambers, \& Sarah, 2016) to the overarching need for teachers to be trained better for teaching children with special needs as the more knowledge and experience the teacher had with these children, the better their perception of IE and self-efficacy would be (Yada \& Savolainen, 2017; Torgbenu et al., 2019; Magumise \& Sefotho, 2020). Dispute the wide variety of challenges, negative attitudes, perceptions and issues an overall trend could be seen by authors choosing to focus on that overall that stakeholders view IE as a way to as Magumise and Sefotho (2020) explains to allow for equal opportunities among learners and to cut down on discrimination.

These articles focused on all aspects of stakeholders except for the children themselves who are attending mainstream schools as part of IE. And while it must be noted that often a very limited conception of IE was used in terms of the children served, nevertheless, these articles gave a voice to parents (Iraq, Samoa, Singapore, Zimbabwe, Nigeria), school leaders (Oman, Georgia), school children/peers (Saudi Arabia), government leaders (Georgia), teachers (Samoa, China, South Korea, Japan, Georgia, Brunei, Zimbabwe, Seychelles, Ghana), NGOs (Kazakhstan) and policies (New Zealand, Solomon Islands, China, South Korea, Malaysia). While many articles focused on more than one specific area, this broad range of articles could be quite indicative of the overall literature on inclusive education and what the emphasis tends to be on. In this case, it seems that teachers, parents and policies might be the most focused on topics. While the majority of the articles directed attention to one specific stakeholder, there is, nonetheless, a prominence given in the literature to the fundamental need for all the stakeholders to work together to overcome the myriad of barriers for successful implementation of IE.

All stakeholders bear a shared responsibility for the commitment to IE and ensuring that each child in inclusive education can succeed, not just academically but emotionally and socially (Koay, 2014). For without government policies that are clear, such as those mentioned in Zimbabwe by Magumise and Sefotho (2020), those that are not truly inclusive such as the 'eligibility dilemmas' mentioned by Jelas and Ali (2014) or where there is no public mandate for public schools to actually accept children with disabilities mentioned by $\mathrm{An}, \mathrm{Hu}$ and Horn (2018), successful implementation of IE can be quite difficult. As how can a school leader, who is often a catalyst for successful implementation of any policies within a school, be able to be a catalyst for change when the policies are unclear (Al-Mahdy \& Emam, 2018). Thus, a direct effect will be realized on school culture and teachers. Kim (2014) mentioned the difficulty in South Korea when school principals have a lack of understanding and inadequate involvement in the actual promotion of inclusionary school practices and the effect that is on school culture. Al-Mahdy and Emam (2018) highlights the deep connection between educational effectiveness and school leadership, and that with positive leadership tendencies the commitment of teachers can be stimulated, especially when 
“"prioritizing teachers' needs, views, values, and satisfaction regarding new practices as is the case of inclusive education" (p. 1167). Teachers will be doubly affected if there are no policies regarding post-service or in-service training on inclusive education. For more high self-efficacy beliefs about IE were seen to be directly affected by the amount of training they receive in special education and the direct experiences these teachers have with special needs children, as this is correlated with self-efficacy beliefs. Yada and Savolainen (2017) stress the criticality of both inservice and pre-service to allow for teachers to be able to cope with 'challenging student behavior' as that will allow teacher's perceptions and attitudes towards IE to be shifted more positively (p. 227). And while their focus was on Japanese teachers, as these other articles show, it is also perhaps more of a global aspect that needs to be stressed for all teachers. As Main, Chambers and Sarah (2016) acknowledge that success for true inclusion of all children fixates on the beliefs and attitudes of a teacher, especially as they noted in a country like the Seychelles where IE is a newly introduced idea. However, just like school leaders and administrators, teachers are only part of the equation. For example, Tufue and Dolgoy (2013) explain that while teachers are important, there is also the need for parent and teacher collaboration (p. 276). As Magmuise and Sefotho (2018) note, "effective inclusive education involves learners and their families in daily activities of the school success" (p. 2). Yet, often what the literature failed to focus on was the actual students themselves.

This succinct look at the literature has allowed for the understanding that where the most change in schools has occurred, regardless of whether that be special education schools or inclusive education, it has been as a consequence by parents pushing for more services. This tool utilized by parents is becoming increasingly more popular among parents with disabled children, yet still has much room for growth. So, while Kim (2014) mentions that some parents in South Korea garner 'abnormal enthusiasm' for IE, often it is not the case as shown by these other articles (p. 984). Wong et al. (2015) highlights that the role that parents play in the initiation and upkeep of IE and support for it is pivotal. Their findings that a parent's understanding of the disability affects the level of involvement of the parent in the school and also their hopes for their child in IE is incredibly important (Wong et al., 2015). This is especially vital as so many other articles stressed that parents too frequently have limited knowledge on disabilities and the benefits of IE as does often the community at large. Kavelashvili's (2017) article sheds light on that before 2006 in Georgia about $95 \%$ of the population of the country had never heard about IE. This is where many articles saw the need for NGOs (Rollan \& Somerton, 2019), children in the classroom (Dare, Nowicki, \& Felimban 2016) and the local community to help with the successful implementation of IE and the school culture that is affected by it. Thus, for true change to occur, it must come from more awareness by each level of stakeholders. However, as this discussion has elucidated, this awareness must come by addressing the multitude of interconnected barriers at the societal, developmental and governmental level.

\section{Conclusions}

There are many limitations when it comes to this study such as the use of one article for each country and using that to generalize not just the country but a region. Nevertheless, there are clear implications of the findings, especially the barriers and issues that arose. These have clear significance in the policy creations on behalf of a government and how they must contemplate and reflect on their cultural context and the implications that will have. For it is not just the IE policies created that will be affected but how they will be viewed and interpreted by the stakeholders, including the varied communities, as well as the school culture. Any policy on IE needs to reflect 
those key areas. These findings also underscore a need for teacher development, both pre-service and in-service and a need for public awareness. Thus, there is plenty of room for further research to see how regional and global these issues really are and to see more of the distinct roles that the stakeholders play in the realization of IE. As the realization of IE will encompass all stakeholders. There are many barriers that have been emphasized by these articles, however, there were also many cultural and historical aspects of the individual countries that could be advantageous for IE policies. Hence, there is also the need for culturally specific policies to be created. These beneficial aspects must be seen in line with the individual and overall global barriers. As has been shown, these barriers must be looked at as a continuum, not individual barriers to be solved one at a time. As these barriers are very interconnected. Many other trends and key themes were found throughout these 18 articles that showcased many of the challenges, concerns, attitudes and even limitations as global issues, regional issues and issues of developing and developed countries. Each article focused on a different country and was able to add their perspective, albeit perhaps limitedly, to the global issue of IE and how to implement it, how to create policies and how to raise awareness of the benefits of IE. Although similarities did arise when it comes to challenges, barriers and attitudes, each is likely to manifest itself differently in each country. This then can reinforce major issues but can also stress the need for less policy borrowing and more focus on the individuality and characteristics of each country. Each author, in terms of their respected countries, contextualized these issues in different ways but they all shine a light on the need for a country to create policies that reflect their own history, cultures and limitations. It also proves that there is no set destination for successful inclusive education, as the journey must be one that is individualized for each country.

\section{References}

Ainscow, M., \& Sandill, A. (2010). Developing Inclusive Education Systems: The Role of Organisational Cultures and Leadership. International Journal of Inclusive Education, 14(4), 401-416. https://doi.org/10.1080/13603110802504903

Alborz, A., Slee, R., \& Miles, S. (2013). Establishing the foundations for an inclusive educationsystem in Iraq: reflection on findings from a nationwide survey. International Journal of Inclusive Education, 17(9), 965-987. https://doi.org/10.1080/13603116.2012.725776

Allan, J. (2006). The Repetition of Exclusion. International Journal of Inclusive Education, 10 (2-3), 121133. https://doi.org/10.1080/13603110500221511

Al-Mahdy, Y. F. H, \& Emam, M. M. (2018). 'Much ado about something' how school leaders affect attitudes towards inclusive education: the case of Oman. International Journal of Inclusive Education, 22(11), 1154-1172. https://doi.org/10.1080/13603116.2017.1417500

An, Z. G., Hu, X., \& Horn, E. (2018). Chinese Inclusive Education: The Past, Present, and Future. Intervention in School and Clinic, 54(2), 118-122. https://doi.org/10.1177/1053451218765244

Booth, T., \& Ainscow, M. (1998). From Them to Us: An International Study of Inclusion in Education. Routledge.

Booth, T., \& Ainscow, M. (2011). The Index for Inclusion (3rd ed.). Centre for Studies in Inclusive Education.

Carrington, S., Pillay, H., Tones, M., Nickerson, J., Duke, D., Benedict, E., Malefoasi, B. A., \& Fa'asala C. J. (2017). A case study of culturally informed disability-inclusive education policy development in the Solomon Islands. International Journal of Inclusive Education, 21(5), 495-506. https://doi.org/10.1080/13603116.2016.1218952 
Clinton, B. (2009, May 19). Statement to Miami Herald in connection with taking up position as US Envoy to Haiti following the hurricane disaster. Miami Herald. http://www.mcclatchydc.com/ 2009/05/19/68410/bill-clinton-named-special-envoy.html

Dare, L., Nowicki, E., \& Felimban, H. (2017). Saudi children's thoughts on inclusive education. International Journal of Inclusive Education, 21(5), 532-543. https://doi.org/10.1080/ $\underline{13603116.2016 .1218948}$

de Boer, A., Pijl, S. J., \& Minnaert, A. (2010). Attitudes of parents towards inclusive education: a review of the literature. European Journal of Disabilities Education, 25(2), 165 - 181. https://doi.org/10.1080/ $\underline{08856251003658694}$

Fei, X. (2007). The Chinese "learning in a regular" classroom: History, current situation, and prospects. Chinese Education and Society, 40 (4), 8-20.

Forlin, C. (2013). Issues of inclusive education in the 21st century. Gakushu Kai- hatsugaku Kenkyu, 6, 6781. https://ir.lib.hiroshimau.ac.jp/files/public/3/35243/20141016204633474404/JEducSci_6_67.pdf

Jelas, Z. M., \& Ali, M. M. (2014). Inclusive education in Malaysia: policy and practice. International Journal of Inclusive Education, 18(10), 991-1003. https://doi.org/10.1080/13603116.2012.693398

Kavelashvili, N. (2017). Inclusive Education in Georgia: Current Progress and Challenges.Challenges of the Future, 2(2), 89-101. https://www.fos-unm.si/media/pdf/Izzivi\%20prihodnosti/Kavelashvili_17.pdf

Kim, Y. W. (2014). Inclusive education in South Korea. International Journal of Inclusive Education, 18(10), 979-990. https://doi.org/10.1080/13603116.2012.693402

Koay, T. L. (2014). Inclusion in Brunei Darussalam: the role of teacher education. International Journal of Inclusive Education, 18(10), 1029-1037. https://doi.org/10.1080/13603116.2012.693396

Kuyini, A. B., Desai, I., \& Sharma, U. (2018). Teachers' self-efficacy beliefs, attitudes and concerns about implementing inclusive education in Ghana, International Journal of Inclusive Education, 24(14), 15091526. https://doi.org/10.1080/13603116.2018.1544298

Lei, J. \& Deng, M. (2007). On Several Relations in the Process of Developing Inclusive Education. Chinese Education \& Society, 40(4), 33-43. https://doi.org/10.2753/CED1061-1932400403

Lo, L. N. (2007). The Sustainable Development of Inclusive Education. Chinese Education \& Society, 40(4), 44-62. https://doi.org/10.2753/CED1061-1932400404

Magumise, J., \& Sefotho, M. M. (2020). Parent and teacher perceptions of inclusive education in Zimbabwe. International Journal of Inclusive Education, 24(5), 544-560. https://doi.org/10.1080/ 13603116.2018 .1468497

Main, S., Chambers, D. J., \& Sarah, P. (2016). Supporting the transition to inclusive education: teachers' attitudes to inclusion in the Seychelles. International Journal of Inclusive Education, 20(12), 1270-1285. https://doi.org/10.1080/13603116.2016.1168873

McDonald, L., \& Tufue-Dolgoy, R. (2013). Moving Forwards, Sideways or Backwards? Inclusive Education in Samoa. International Journal of Disability, Development and Education, 60(3), 270-284. https://doi.org/10.1080/1034912X.2013.812187

Mitchell, D. (2010). Education That Fits: Review of International Trends in the Education of Students with SEN: Final Report. Christchurch: College of Education, University of Canterbury.

Ngan-Woo, F. (1985). Fa'aSamoa - the world of Samoans. Office of the Race Relations Conciliator

Rollan, K., \& Somerton, M. (2019). Inclusive education reform in Kazakhstan: civil society activism from the bottom-up, International Journal of Inclusive Education, 1-16. https://doi.org/10.1080/13603116 .2019 .1599451 
Salend, S. J. (1998). Effective Mainstreaming: Creating Inclusive Classrooms (3rd ed.). Prentice-Hall.

Selvaraj, J. (2015). Inclusive education in New Zealand: policies, politics and contradictions. International Journal of Inclusive Education, 19(1), 86-101. https://doi.org/10.1080/13603116.2014.907584

Slee, R. (1996). Clauses of conditionality: The "reasonable" accommodation of language. In L. Barton (Ed.), Disability and society: Emerging issues and insights (pp. 107-122). Longman.

Slee, R. (2006). Inclusive Education: Is This Horse a Trojan?. Exceptionality Education Canada 16 (2/3), 223242. https://www.researchgate.net/publication/234676816 Inclusive Education Is This Horse a Trojan

Slee, R. (2010). The irregular school. Exclusion, schooling and inclusive education. Routledge.

Stevens, L., \& Wurf, G. (2020). Perceptions of inclusive education: A mixed methods investigation of parental attitudes in three Australian primary schools. International |Journal of Inclusive Education, 24(4), 351-365. https://doi.org/10.1080/13603116.2018.1464068

Tan, J. B., \& Yates, S. (2011). Academic expectations as sources of stress in Asian students. Social Psychology of Education, 14, 389-407. https://doi.org/10.1007/s11218-010-9146-7

Torgbenu, E. L., Oginni, O. S., Opoku, M. P., Nketsia, W., \& Agyei-Okyere, E. (2019). Inclusive education in Nigeria: exploring parental attitude, knowledge and perceived social norms influencing implementation. International Journal of Inclusive Education, 25(3), 1-19. https://doi.org/10.1080/ $\underline{13603116.2018 .1554715}$

Ueno, K., \& Nakamura, K. (2011). Inkuru-jonkyoiku ni taisuru tsujogakkyukyoin no ishiki ni tsuite [A study of awareness of "Inclusion Education" among regular- class teachers in elementary schools], Journal of Health and Sports Science Juntendo, 3(2), 112-117.

UNESCO. (1994). The Salamanca statement and framework for action on special needs education. Retrieved from: http://unesdoc.unesco.org/images/ 0009/000984/098427eo.pdf.

UNESCO. (2000). The Dakar framework for action: Education for all: Meeting our collective commitments. Retrieved from: http://www.undp.org.lb/programme/governance/institutionbuilding/ basiceducation/docs/dakar.pdf.

UNESCO. (2005). Guidelines for inclusion: Ensuring the access to education for all. Retrieved from: http://unesdoc.unesco.org/images/0014/001402/140224e.pdf.

UNESCO (2008). Defining an inclusive education agenda: Reflections around the 48th session of the International Conference on Education. Retrieved from http://unesdoc.unesco.org/images/ $\underline{0018 / 001868 / 186807 \text { e.pdf. }}$

United Nations. (1948). Universal declaration of human rights. United Nations. http://www.un.org/en/ documents/udhr/index.shtml

United Nations. (2006). Convention on the rights of persons with disabilities. United Nations. http://www.un.org/disabilities/convention/conventionfull.shtml

Wong, M. E., Poon, K. K., Kaur, S., \& Ng, Z. J. (2015). Parental perspectives and challenges in inclusive education in Singapore Asia Pacific Journal of Education, 35(1), 85-97. https://doi.org/ $\underline{10.1080 / 02188791.2013 .878309}$

Yada, A., \& Savolainen, H. (2017). Japanese in-service teachers' attitudes toward inclusive education and self-efficacy for inclusive practices. Teaching and Teacher Education, 64, 222-229. https://doi.org/ $\underline{10.1016 / j . t a t e .2017 .02 .005}$ 